\title{
Rainfall Thresholds as Support for Timing Fungicide Applications in the Control of Potato Late Blight in Ecuador and Peru
}

Peter Kromann, Department of Plant Biology, Faculty of Life Sciences, University of Copenhagen, Thorvaldsensvej 40, Dk-1871 Frederiksberg C, Denmark, and International Potato Center (CIP), P.O. Box 17-21-1977, Quito, Ecuador; Arturo Taipe, CIP, Quito, Ecuador; and Willmer G. Perez and Gregory A. Forbes, CIP, P.O. Box 1558, Lima 12, Peru

\begin{abstract}
Kromann, P., Taipe, A., Perez, W. G., and Forbes, G. A. 2009. Rainfall thresholds as support for timing fungicide applications in the control of potato late blight in Ecuador and Peru. Plant Dis. 93:142-148.

Accumulated rainfall thresholds were studied in seven field experiments conducted in Ecuador and Peru for their value in timing applications of fungicide to control potato late blight, caused by Phytophthora infestans. Fungicide regimes based on accumulated rainfall thresholds ranging from 10 to $70 \mathrm{~mm}$ were compared with calendar spray schemes of every 5 or 7 days. Very low thresholds of 10 to $20 \mathrm{~mm}$ gave similar levels of control and resulted in similar number of sprays as did calendar spraying. However, neither low thresholds nor calendar sprays were effective in protecting susceptible potato genotypes in over half of the experiments. Thresholds of 25 to 50 $\mathrm{mm}$ pf rainfall led to reduction in the number of sprays needed to protect resistant cultivars but also resulted in high levels of disease on susceptible cultivars. We conclude that timing fungicide sprays based on accumulated rainfall thresholds could be a successful component of integrated management strategies that include cultivars with moderate or high levels of resistance. The simplicity of measuring accumulated rainfall means that the technology can potentially be used by resource-poor farmers in developing countries.
\end{abstract}

Additional keywords: knapsack sprayer, mancozeb

Potato late blight, caused by the oomycete Phytophthora infestans, is a severe problem for potato farmers in tropical highlands worldwide (22). In the Andes of South America, it is considered the most important problem facing potato farmers (33). In the highland tropics where potato can be grown year-round, the disease can attack potato foliage from emergence to harvest, and there is some evidence that infections from aerial inoculum may even occur prior to emergence (27). It has been estimated that, on average, $15 \%$ yield loss is caused by late blight in Peru (34) and we expect that the average yield loss is similar in Ecuador. When epidemics become severe and uncontrollable, farmers abandon fields and $100 \%$ yield losses frequently occur (11,35). Additionally, the cost of control is high. We estimate that farmers in the Andes spend between 5 and 20\% of total production costs on fungicides to control late blight, depending on their financial resources and disease pressure. Depending on weather conditions, farmers

Corresponding author: G. A. Forbes

E-mail: g.forbes@cgiar.org

Accepted for publication 5 September 2008.

doi:10.1094/PDIS-93-2-0142

(C) 2009 The American Phytopathological Society in northern Ecuador may spray foliage up to 18 times with translaminar fungicides (33). Due to a generally dryer climate, spraying is less intensive in Peru and in the central and south of Ecuador (36). A survey done in Cajamarca, San Miguel, and Contumaza, Peru indicated that farmers, on average, spray six times with fungicides (34) and we assume that this is still the case. Furthermore, we have unpublished data that show that farmers may spray fungicides up to 15 times to control late blight in Huánuco and Huasahuasi, Peru.

Late blight control in the Andes is based primarily on applying fungicides to foliage through the entire growing season (19). The use of cultivars with appreciable levels of genetic resistance is becoming more popular but most farmers still plant susceptible cultivars (33). Cultural practices for disease control are generally not employed by farmers (36) because farmers generally do not understand the concept (33). The effectiveness of cultural practices has also been questioned by researchers because of constant presence of aerial inoculum (19). Under high disease pressure, management of late blight solely with fungicides may still lead to insufficient control and yield loss or is economically impossible for many farmers. For this reason, many farmers may avoid high disease pressure by planting at high altitudes where temperatures are low or by planting outside the rainy season when low humidity retards disease development $(10,36)$. Escaping the disease in space and time often leads to lower yields because the potato crop is not planted at a site or time for optimal plant growth. This suboptimal production is also characterized by increased risk of crop loss due to frost or drought (21).

For control of leaf and stem late blight, a wide range of systemic, translaminar, and contact fungicides are used. The products most commonly used in Ecuador are dithiocarbamate-type contact fungicides such as mancozeb and propineb and the translaminar compound cymoxanil, although these are sold in many different formulations $(8,26)$.

Poisoning of potato farmers by exposure to fungicides in developing countries is common $(39,40)$. Under highland tropical conditions, farmers are directly exposed to fungicides because application almost always is done with knapsack sprayers and usually without any protective clothing $(7,32)$. Extensive use of dithiocarbamate fungicides was reported to contribute to skin and eye problems in a survey among potato farmers in northern Ecuador (6).

The use of resistant cultivars is potentially the most effective way of reducing dependency on fungicides in potato production $(25,30)$. However, good data for developing integrated packages for the deployment of resistant cultivars in the highland tropics are lacking.

In the industrialized countries, sophisticated decision support systems (DSS) have been developed to assist farmers in making decisions about fungicide application. These systems are generally based on detailed weather data, employ computers to manage the data, and often involve regional coordination. In the highly varied agroecosystem of developing countries, these systems are not used because they require resources farmers do not have or infrastructure that does not exist (16).

Weather conditions, in general, influence the period during which fungicides are effective on potato foliage, because they are subject to degradation by high temperature and photolysis, wash-off by rain, and volatilization (31). Rain can wash off almost all active ingredients of a contact fungicide deposited on a leaf surface $(2,12,23)$. The intensity and duration of 
rainfall influence the rainfastness but total amount of rainfall has been argued to be more important for rainfastness $(2,12)$. In a successful disease simulator, wash off by rain and temperatures above $15^{\circ} \mathrm{C}$ were considered the primary factors affecting persistence of the contact fungicide chlorothalonil (2). Because average daily temperatures in the highland tropical potato production areas are below $15^{\circ} \mathrm{C}$, rainfall would appear to be a primary factor determining fungicide residues after application. Furthermore, rainfall is generally measured and used as a daily average, which is an easy parameter to measure and understand.

In an effort to find DSS appropriate for tropical farmers, researchers experimented in the 1960s with accumulated rainfall thresholds for timing applications of fungicide for the control of potato late blight in Colombia $(1,5)$. This early work concluded that rainfall thresholds of 13 and 25 $\mathrm{mm}$ can be recommended for use in susceptible cultivars. However, for several reasons, it was not known whether these results would be applicable throughout the Andean region and with deployment of resistant cultivars. Consequently, we identified a need to investigate rainfall thresholds under more varying conditions in the Andean highlands and with a broader range of host plant resistance levels. To do this, a series of field experiments were conducted on station or in farmers' fields to investigate the hypothesis that accumulated rainfall thresholds can be used as decision support for timing of contact fungicide applications in the control of potato late blight. Overall, we present data from seven experiments, three in Ecuador and four in Peru.

Table 1. Late blight (Phytophthora infestans) epidemics reflected by relative area under the disease progress curve values (RAUDPC) on potato genotypes grown in seven experiments (three in Ecuador and four in Peru) where different fungicide application regimes based on calendar spraying or rainfall thresholds were employed ${ }^{\mathrm{v}}$

\begin{tabular}{|c|c|c|c|c|c|c|c|c|c|}
\hline \multirow[b]{2}{*}{ Experiment, genotypes $^{x}$} & \multirow[b]{2}{*}{ Figure } & \multirow[b]{2}{*}{$\operatorname{MSP}(\text { days })^{y}$} & \multirow[b]{2}{*}{ Calendar $^{z}$} & \multicolumn{6}{|c|}{ RAUDPC at rainfall thresholds ( $\mathrm{mm}$ rainfall) ${ }^{\mathrm{w}}$} \\
\hline & & & & 10-15 & 18-20 & $25-35$ & $40-50$ & 70 & Unsprayed \\
\hline Ecuador 2002 & & & & (10) & (18) & $(30)$ & & & \\
\hline Papa Pan & $1 \mathrm{~A}$ & 10 & - $\underline{0.01 \mathrm{c}}$ & $\underline{0.01 \mathrm{c}}$ & $\square \underline{0.01 \mathrm{c}}$ & $\Delta \underline{0.02 b}$ & $\ldots$ & $\ldots$ & घ $0.11 \mathrm{a}$ \\
\hline Santa Catalina & 1B & 7 & $\overline{0.02 \mathrm{~d}}$ & $\overline{0.03 \mathrm{~d}}$ & $\square \underline{\underline{0.04 \mathrm{c}}}$ & $\Delta \overline{0.09 \mathrm{~b}}$ & $\ldots$ & $\ldots$ & $0.17 \mathrm{a}$ \\
\hline Gabriela & $1 \mathrm{C}$ & 5 & $\overline{0.06 \mathrm{~d}}$ & $\overline{0.07 \mathrm{~d}}$ & $\square \overline{0.12 \mathrm{c}}$ & $\Delta 0.22 \mathrm{~b}$ & $\ldots$ & $\ldots$ & ש $0.42 \mathrm{a}$ \\
\hline Applications & $\ldots$ & $\ldots$ & 11 & 12 & 8 & 5 & & & $\ldots$ \\
\hline Ecuador 2003 & & & & & & $(30)$ & $(50)$ & $\ldots$ & \\
\hline Papa Pan & & 10 & $\underline{0.02 \mathrm{~b}}$ & $\ldots$ & $\ldots$ & $\underline{0.02 \mathrm{~b}}$ & $\underline{0.03 \mathrm{~b}}$ & $\ldots$ & $0.18 \mathrm{a}$ \\
\hline $97-1-8$ & $1 \mathrm{D}$ & 10 & $\underline{0.02 \mathrm{~b}}$ & $\ldots$ & $\ldots$ & $\square \overline{\underline{0.03 \mathrm{~b}}}$ & $\Delta \underline{0.04 \mathrm{~b}}$ & $\ldots$ & - $0.16 \mathrm{a}$ \\
\hline $97-1-10$ & $\ldots$ & 10 & $\underline{0.01 \mathrm{~b}}$ & $\ldots$ & $\ldots$ & $\underline{0.02 \mathrm{~b}}$ & $\underline{0.03 \mathrm{~b}}$ & $\ldots$ & $0.20 \mathrm{a}$ \\
\hline $97-1-2$ & $1 \mathrm{E}$ & 10 & $\overline{0.02 \mathrm{~b}}$ & $\ldots$ & $\ldots$ & $\square \overline{0.02 \mathrm{~b}}$ & $\Delta \overline{0.04 b}$ & $\ldots$ & - $0.25 \mathrm{a}$ \\
\hline $97-25-3$ & $\ldots$ & 10 & $\overline{0.01 \mathrm{~b}}$ & $\ldots$ & $\ldots$ & $\underline{0.01 \mathrm{~b}}$ & $\underline{0.04 \mathrm{~b}}$ & $\ldots$ & $0.16 \mathrm{a}$ \\
\hline LBR-37 & $1 \mathrm{~F}$ & 10 & $\overline{0.10 \mathrm{c}}$ & $\ldots$ & $\ldots$ & $\square \overline{0.12 \mathrm{bc}}$ & $\Delta \overline{0.18 b}$ & $\ldots$ & - $0.39 \mathrm{a}$ \\
\hline Applications & $\ldots$ & $\ldots$ & 9 & $\ldots$ & $\ldots$ & 5 & 3 & $\ldots$ & $\ldots$ \\
\hline Ecuador 2005 & & & & & & & $(50)$ & & \\
\hline $97-1-8$ & $2 \mathrm{~A}$ & 10 & $0.01 \mathrm{c}$ & $\ldots$ & $\ldots$ & $\ldots$ & $\Delta 0.05 \mathrm{~b}$ & $\ldots$ & - $0.11 \mathrm{a}$ \\
\hline Fripapa & $\ldots$ & 10 & $\overline{0.01 \mathrm{~b}}$ & $\ldots$ & $\ldots$ & $\ldots$ & $\overline{0.07 \mathrm{~b}}$ & $\ldots$ & $0.21 \mathrm{a}$ \\
\hline $97-1-2$ & $2 \mathrm{~B}$ & 10 & $\overline{0.02 \mathrm{~b}}$ & $\ldots$ & $\ldots$ & $\ldots$ & $\Delta \overline{0.12 b}$ & $\ldots$ & 口 $0.34 \mathrm{a}$ \\
\hline $97-1-6$ & & $\ldots$ & $\underline{0.04 \mathrm{c}}$ & $\ldots$ & $\ldots$ & $\ldots$ & $0.13 \mathrm{~b}$ & $\ldots$ & $0.34 \mathrm{a}$ \\
\hline Superchola & $2 \mathrm{C}$ & $\ldots$ & $\overline{0.04 \mathrm{c}}$ & $\ldots$ & $\ldots$ & $\ldots$ & $\Delta 0.22 \mathrm{~b}$ & $\ldots$ & - $0.37 \mathrm{a}$ \\
\hline Applications & $\ldots$ & $\ldots$ & 12 & $\ldots$ & $\ldots$ & $\ldots$ & 5 & $\ldots$ & $\ldots$ \\
\hline Peru 2003 & & & & & (20) & $(30)$ & & & \\
\hline Pericholi & $2 \mathrm{D}$ & 4 & - $0.07 \mathrm{~b}$ & $\ldots$ & $\square 0.10 \mathrm{~b}$ & $\Delta 0.19 \mathrm{~b}$ & $\ldots$ & $\ldots$ & च $0.36 \mathrm{a}$ \\
\hline Amarilis & $2 \mathrm{E}$ & 4 & $\underline{0.10 \mathrm{~b}}$ & $\ldots$ & $\square 0.10 \mathrm{~b}$ & $\boldsymbol{\Delta} 0.26 \mathrm{ab}$ & $\ldots$ & $\ldots$ & - $0.47 \mathrm{a}$ \\
\hline Desiree & $2 \mathrm{~F}$ & 4 & $\overline{0.26 b}$ & $\ldots$ & $\square 0.43 \mathrm{ab}$ & $\Delta 0.57 \mathrm{ab}$ & $\ldots$ & $\ldots$ & - $0.63 \mathrm{a}$ \\
\hline Applications & $\ldots$ & $\ldots$ & 11 & $\ldots$ & 9 & 9 & $\ldots$ & $\ldots$ & $\ldots$ \\
\hline Peru 2004 & & & & & (15) & $\square(25)$ & $\cdots$ & $\cdots$ & $\ldots$ \\
\hline & $\ldots$ & $\cdots$ & $\cdots$ & $\cdots$ & & $\Delta(35)$ & $\ldots$ & $\ldots$ & $\cdots$ \\
\hline Yungay & $3 \mathrm{C}$ & 4 & $\ldots$ & $\ldots$ & $0 \underline{0.06 \mathrm{c}}$ & $\square 0.24 \mathrm{~b}$ & $\ldots$ & $\ldots$ & - $0.60 \mathrm{a}$ \\
\hline & $\ldots$ & $\ldots$ & $\ldots$ & $\ldots$ & $\ldots$ & $\mathbf{\Delta} 0.26 \mathrm{~b}$ & $\ldots$ & $\ldots$ & $\ldots$ \\
\hline Applications & $\ldots$ & $\ldots$ & $\ldots$ & & 14 & $\square 8$ & $\ldots$ & $\ldots$ & $\ldots$ \\
\hline & & $\ldots$ & $\ldots$ & $\ldots$ & $\ldots$ & $\Delta 6$ & $\ldots$ & $\ldots$ & $\ldots$ \\
\hline Peru 2005 & & & & & & (30) & $(50)$ & (70) & \\
\hline 391580.30 & $3 \mathrm{~A}$ & $5,7,10$ & $\underline{0.01 \mathrm{c}}$ & $\ldots$ & $\ldots$ & $\square \underline{0.03 \mathrm{bc}}$ & $0.09 \mathrm{bc}$ & $\Delta 0.11 \mathrm{~b}$ & 口 $0.29 \mathrm{a}$ \\
\hline 393385.39 & 3B & $5,7,10$ & $0 \overline{0.04 \mathrm{c}}$ & $\ldots$ & $\ldots$ & $\square \overline{0.19 \mathrm{c}}$ & $\bigcirc 0.40 \mathrm{~b}$ & $\Delta 0.40 \mathrm{~b}$ & च $0.68 \mathrm{a}$ \\
\hline Applications & $\ldots$ & $\ldots$ & 13 & $\ldots$ & $\ldots$ & 6 & 4 & 3 & $\ldots$ \\
\hline Peru 2006 & & & & & & & $(40)$ & & \\
\hline Cruza 148 & $3 \mathrm{D}$ & 7 & - $\underline{0.01 \mathrm{a}}$ & $\ldots$ & $\ldots$ & $\ldots$ & $\Delta \underline{0.01 \mathrm{a}}$ & $\ldots$ & $\mathrm{D} \underline{0.01 \mathrm{a}}$ \\
\hline Yungay & $3 \mathrm{E}$ & 7 & $\overline{0.06 \mathrm{~b}}$ & $\ldots$ & $\ldots$ & $\ldots$ & $\Delta \overline{0.12 \mathrm{ab}}$ & $\ldots$ & $\square \overline{0.25 \mathrm{a}}$ \\
\hline 386209.10 & ... & 7 & $0.10 \mathrm{~b}$ & $\ldots$ & $\ldots$ & $\ldots$ & $0.13 \mathrm{ab}$ & $\ldots$ & $0.27 \mathrm{a}$ \\
\hline Musuq & $3 \mathrm{~F}$ & 7 & $0.15 \mathrm{a}$ & $\ldots$ & $\ldots$ & $\ldots$ & $\Delta 0.39 \mathrm{a}$ & $\ldots$ & 口 $0.44 \mathrm{a}$ \\
\hline Applications & $\ldots$ & $\ldots$ & 11 & $\ldots$ & $\ldots$ & $\ldots$ & 5 & $\ldots$ & $\ldots$ \\
\hline
\end{tabular}

${ }^{\mathrm{v}}$ Underlined data indicate a successful late blight control in the application regime-genotype-combination. Treatments were considered successful if they maintained disease severity below $20 \%$ until 100 days after planting. Symbols $(\boldsymbol{\bullet}, \bigcirc, \boldsymbol{\Lambda}, \square$, and $\mathbf{\square})$ are identifiers to each disease progress curve that can be found in Figures 1-3.

${ }^{\mathrm{w}}$ Column headings indicate the rainfall range of the treatment thresholds; the specific rainfall threshold applied for each treatment is given in parentheses. Treatment values followed by different letters in the same experiment are significantly different (Tukey's 5\%).

${ }^{\mathrm{x}}$ Ecuador in 2002 and 2003 were done at the Santa Catalina experiment station of the International Potato Center (CIP) near Quito, Ecuador, 3,058 m above sea level (masl); Ecuador in 2005 was done in northern Ecuador in the province of Carchi, 2,938 masl.; Peru in 2003 and 2004 were done in Comas in the province of Junin, 2,800 masl.; Peru in 2005 was done near Huánuco, 2,510 masl; and Peru in 2006 was done in Huasahuasi, 3,292 masl. Applications: number of applications of fungicide for each treatment. Fungicide applications applied immediately after emergence to protect plants until they reached a minimum size for the experiment are not included.

${ }^{y}$ MSP is the minimum period between sprays regardless of the rainfall. This did not affect the calendar spray. In the experiment in Peru in 2005 , the period was variable: 5,7 , and 10 days for 30,50 , and $70 \mathrm{~mm}$, respectively.

${ }^{\mathrm{z}}$ The calendar spray regime was either every 5 days (Peru in 2003, 2004, and 2005) or every 7 days until plants reached senescence. 


\section{MATERIALS AND METHODS}

The research described in this article involves experiments performed in the highland tropics of Ecuador and Peru in areas of more than $2,800 \mathrm{~m}$ above sea level. The seven experiments were done between 2002 and 2006 on the International Potato Center's experiment station near Quito, Ecuador or on farmers' fields in Ecuador or Peru.

Potato genotypes and fungicide treatments. The potato genotypes used in each of the experiments varied from between one and six and had diverse levels of late blight resistance. Fungicide treatments consisted of applications of mancozeb after accumulated rainfall thresholds ranging from 10 to $70 \mathrm{~mm}$ (Table 1). In each experiment, threshold treatments were compared with a calendar spray scheme consisting of sprays every 5 or 7 days and a control treatment without fungicide application, except in one experiment in Peru in 2004 involving only one susceptible genotype, where no calendar sprays were included. All spray programs were continued until plants reached senescence (i.e., beginning of leaf yellowing). The experiment in Peru in 2004 originally included other potato genotypes, which were excluded because they were immune to the $P$. infestans population at the site and no late blight epidemics occurred. All fungicide treatments in all experiments were done using the contact fungicide Dithane M-45 (Dow AgroSciences Ltd.), which contains $80 \%$ mancozeb, at the manufacturer's recommended dose of active ingredient at $2 \mathrm{~g}$ liter $^{-1}$. In all experiments, fungicide was applied with a 20-liter lever-operated knap-
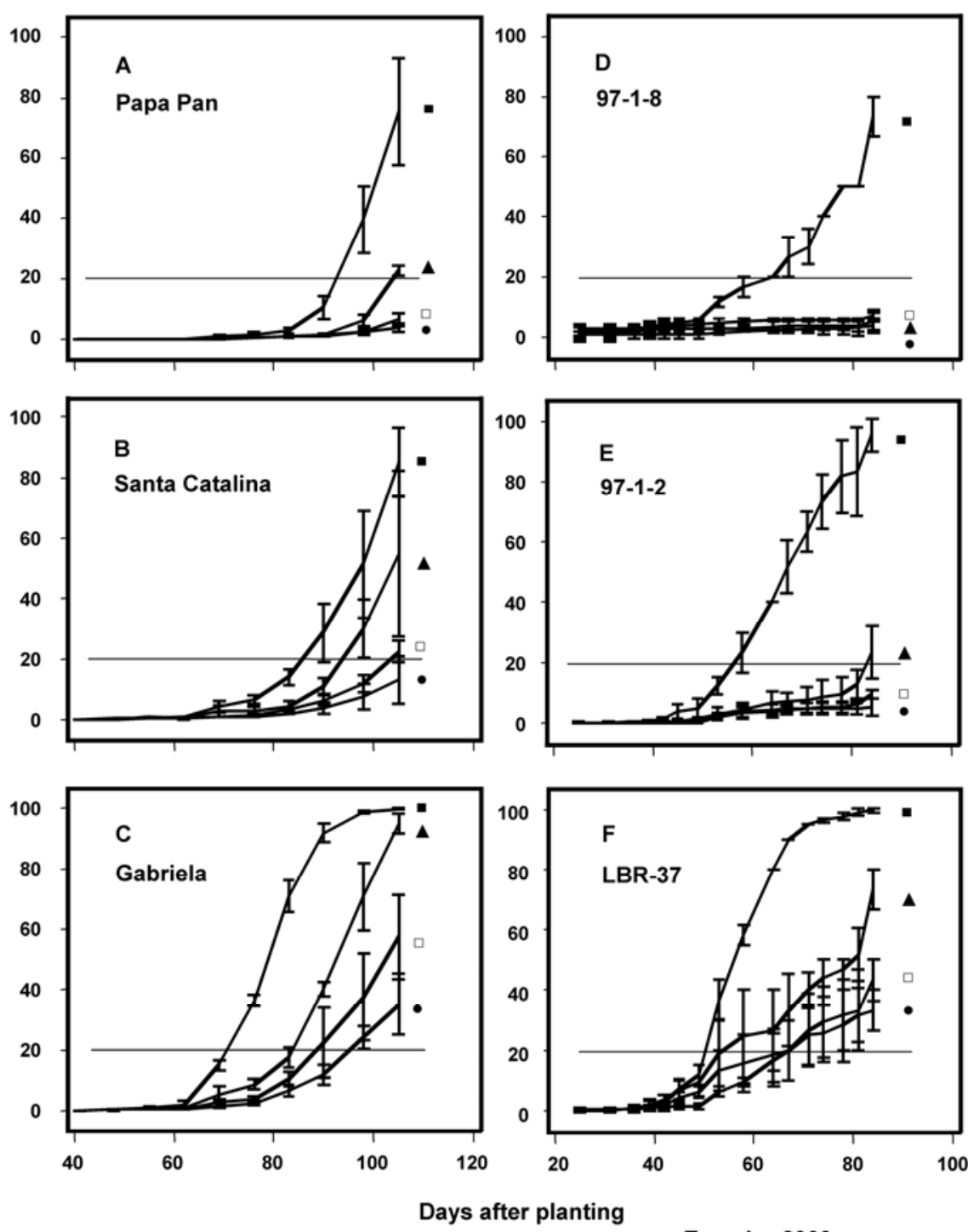

Ecuador 2002

Days after planting

Ecuador 2003

Fig. 1. Potato late blight (Phytophthora infestans) disease progress curves for epidemics in selected potato genotypes (name of cultivar or breeding line no. in upper left corner) in experiments in Ecuador in A, B, and C, 2002 and $\mathbf{D}, \mathbf{E}$, and $\mathbf{F ,} 2003$ with treatments consisting of fungicide regimes based on calendar spraying or rainfall thresholds. Error bars indicate standard deviations for replicate plots. Symbols $(\boldsymbol{\bullet}, \boldsymbol{\Lambda}, \square$, and $\mathbf{\square})$ can be used to identify corresponding data described in Table 1 (e.g., $\mathbf{\square}=$ unsprayed treatment and $\mathbf{O}=$ calendar spray treatment [7-day spray interval]). sack sprayer. Constant flow valves were used (CFValve R11-16SY; G.A.T.E, Sebastian, FL) along with hollow cone nozzles having exit holes of either 0.8 or $1.2 \mathrm{~mm}$, and fungicide was applied until runoff.

Precipitation was measured on site with conventional manual rainfall gauges and with automated rainfall dataloggers (Spectrum Technologies, Inc., Plainfield, IL, and Onset Computer Corporation, Bourne, MA). Rainfall thresholds were selected for each experiment on the basis of previous assumptions about the levels of host resistance of selected genotypes and the results from earlier experiments. To prevent too frequent sprays in the threshold treatments, should a threshold be reached two or more days consecutively, minimum application periods were employed between two consecutive applications. The minimum number of days between sprays was set between 4 and 10 according to threshold level or the genotype resistance level for each experiment (Table 1). Highly resistant genotypes were not available for each experiment or data were excluded because of the problem of incompatibility described above.

Experimental design and agronomic practices. Each experiment was set up as a two-way factorial with the two factors being fungicide treatment and potato genotype. In all experiments, each two-factor combination was repeated in three plots. Experiments done in Ecuador in 2002 and Peru in 2004 used a randomized complete block design (RCBD); experiments in Ecuador in 2003 and 2005 used a split-plot design; and experiments in Peru in 2003, 2005, and 2006 used a strip-plot design.

Planting was done following local practices at each location but, in all cases, distance was approximately $0.9 \mathrm{~m}$ between rows and $0.35 \mathrm{~m}$ within rows. In Ecuador, experimental units consisted of 52 to 75 plants. In Peru, the experimental units were smaller, consisting of only 20 to 40 plants. All experiments were planted to coincide with the rainy season in both countries (i.e., between November and February), which is also the period of greatest late blight disease pressure. To help differentiate experimental units and to reduce interplot inoculum interference, 0.5 to $2 \mathrm{~m}$ of cereal (Avena sativa or Hordeum vulgarum) was planted between all potato plots. Insect and weed control using herbicides and insecticides, as well as fertilization, were done according to local integrated crop management recommendations. In all experiments, potato plants were killed by late blight or left to senescence naturally before harvest.

Disease evaluation and data analysis. After emergence, potato plants were protected against late blight by fungicide sprays applied uniformly to all plots in the experiment in an effort to prevent any infection until plants had reached a minimum size of 15 to $25 \mathrm{~cm}$. This protection 
period generally corresponded to a period of 35 days past planting. In the experiments in Ecuador, a single spray with a fungicide containing propamocarb or cymoxanil was applied at approximately 30 days after planting to all treatments, including the control treatment, without fungicide application. In the experiments in Peru, potato plants in all treatments, including treatments to be left without fungicide application, were sprayed weekly with the contact fungicide Dithane M-45 between $80 \%$ emergence and 30 days after planting. Approximately 10 days after the last of these initial sprays, the experimental fungicide treatments were initiated. Percent foliage affected in leaves and stems was estimated visually at the plot level beginning at the first symptoms and continuing every 4 to 7 days until susceptible plants had died or the experiment was otherwise terminated. Disease assessment readings were used to calculate the area under the disease progress curve (AUDPC) using the midpoint rule (3). The AUDPC was then transformed into the relative AUDPC (RAUDPC) as previously described (18). Analysis of variance and means comparison procedures (Tukey's) were used to compare treatments in each experiment. A separate analysis was run for each genotype in each experiment. To facilitate interpretation of results, treatments were considered successful if they maintained disease severity below $20 \%$ until 100 days after planting, and this criterion is used throughout the text as successful control. Statistical analyses were done using SAS 9.1 statistical software (SAS Institute Inc., Cary, NC).

\section{RESULTS}

Comparison of RAUDPC values (Table 1) and disease progress curves (Figs. 1-3) indicated some general patterns in the utility of rainfall thresholds as a tool for supporting late blight spray decisions. Low thresholds (10 to $20 \mathrm{~mm}$ ) were similar to calendar spraying in all cases, which indicates that rainfall was generally frequent throughout the periods of the experiments. Thresholds of 25 to $35 \mathrm{~mm}$ of rainfall resulted in significant reductions in the number of sprays (Table 1); however, these thresholds did not always lead to successful disease control.

The higher thresholds (40 to $70 \mathrm{~mm}$ ), which gave significant spray reductions, tended to work when the potato genotype had an appreciable level of resistance, which can be loosely derived from the RAUDPC values of the unsprayed treatments (Table 1). In the three trials in Ecuador, the level of control in at least one resistant genotype was considered successful at the 30-mm threshold in 2002 and the 50-mm threshold in 2003 and 2005. This was fairly consistent, as evidenced by genotypes $97-1-8$ and $97-1-2$ that were repeated in experiments in Ecuador 2003 and 2005 and had fairly similar results in both years. With the resistant potato genotypes, use of the 50-mm threshold reduced sprays in 2002 to 5 compared with 11 for the calendar spray treatment, and in 2003 from 9 to 3 .

In Peru, thresholds worked less well, only controlling disease in a few cases. However, in Peru, either disease pressure was higher or the potato genotypes were less resistant, because RAUDPC values tended to be higher. In 2006, RAUDPC values were not as high but this appeared to result from low disease pressure early in the season that later intensified (Fig. 3). A threshold of $15 \mathrm{~mm}$ worked in Peru in 2004 for cv. Yungay but this threshold resulted in 14 sprays (there was no calendar spray treatment for comparison in this experiment). Significant spray reductions occurred with the 40-mm threshold and cv.
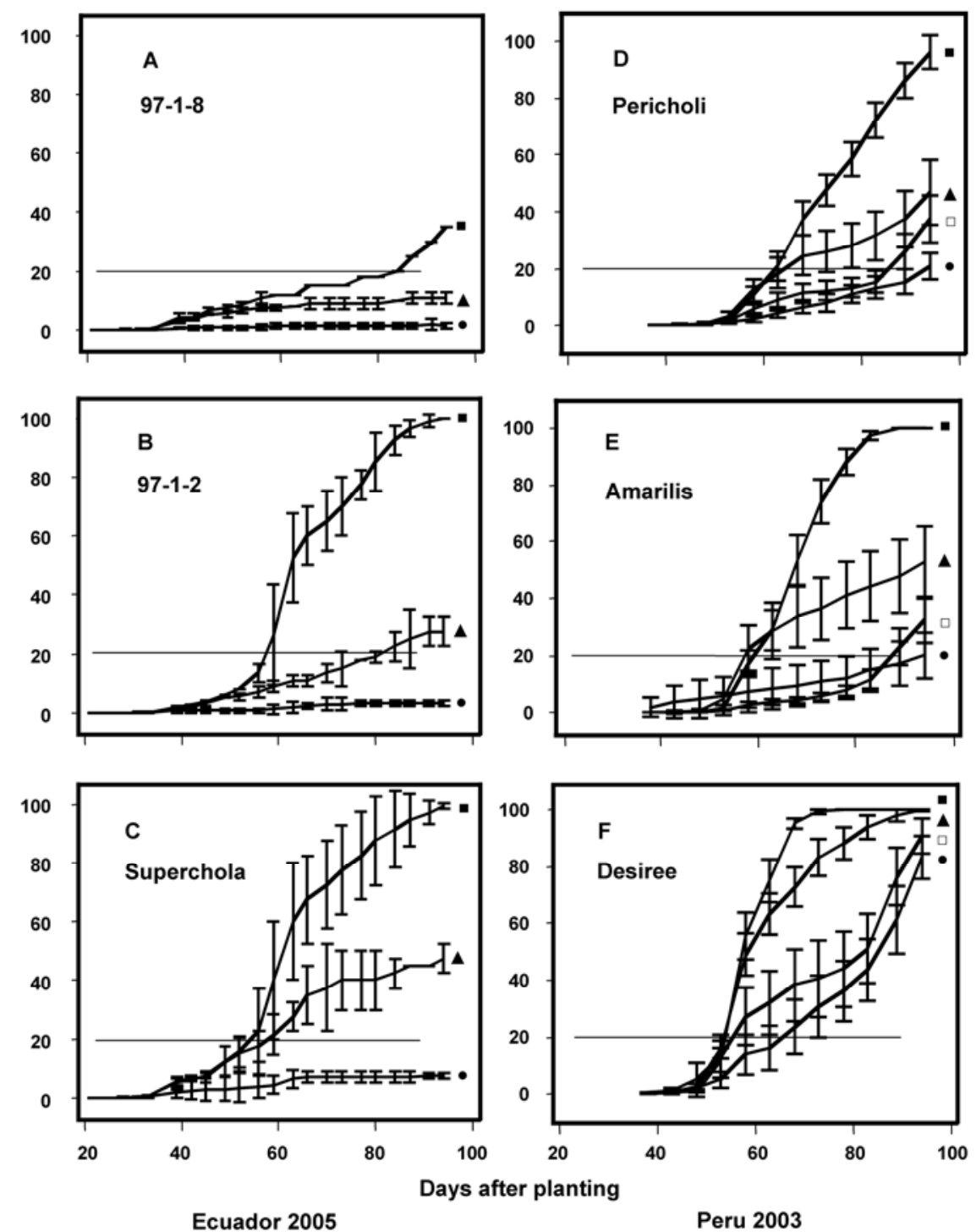

Fig. 2. Potato late blight (Phytophthora infestans) disease progress curves for epidemics in selected potato genotypes (name of cultivar or breeding line no. in upper left corner) in experiments in A, B, and $\mathbf{C}$, Ecuador in 2005 and D, E, and F, Peru in 2003 with treatments consisting of fungicide regimes based on calendar spraying or rainfall thresholds. Error bars indicate standard deviations for replicate plots. Symbols $(\boldsymbol{\bullet}, \boldsymbol{\Lambda}, \square$, and $\boldsymbol{\square})$ can be used to identify corresponding data described in Table 1 (e.g., - = unsprayed treatment and $\boldsymbol{Q}=$ calendar spray treatment [5- or 7-day spray interval]).

Cruza 148 in 2006 in Peru; however, the unsprayed control of this cultivar also had very little disease. In a number of experiments, disease was not controlled in geno-
types with low levels of resistance with any of the thresholds; nor was it controlled with the calendar spray treatment (e.g., Gabriela in Ecuador 2002, Desiree in Peru 2003, and Yungay and Musuq in Peru

\section{DISCUSSION}

The results from 5 years of experimental can be used under certain circumstances by resource-poor farmers in the highland tropics as decision support for applying fungicides more effectively and safely. Thesholds of under $20 \mathrm{~mm}$ appeared to work generally with any potato genotype
that has a moderate level of resistance but

Plant Disease / February 2009

145 
these thresholds did not save much in fungicide usage in our study. However, this result could be different for areas where rainfall is more irregular during the potato growing season.

Higher thresholds, up to $50 \mathrm{~mm}$, resulted in significant reductions in fungicide applications compared with calendar spraying. However, these thresholds require genotypes with significant levels of resistance, and herein lies the difficulty of this type of research. At this time, it is not easy to develop clear guidelines for the type of threshold that may be used for a given level of resistance because, at present, a good quantitative scale for comparing levels of resistance under tropical short-day conditions does not exist. European researchers have recently made progress in the refinement of resistance classification of European potato cultivars (20) but their system requires one or more stan- dard cultivars, which at present do not exist for the highland tropics.

Based on the RAUDPC, it appeared that, with the exception of Cruza 148, genotypes used in Peru were generally less resistant than those in Ecuador; however, the differences in RAUDPC may also indicate that disease pressure was higher in Peru. The particular case of Cruza 148 is puzzling. This cultivar is well known for its long-standing field resistance but it generally does get some level of infection. In an international late blight resistance stability study, it was always resistant but was not the most resistant genotype in the study (14). In Peru in 2006, Cruza 148 was virtually immune, and that effectively nullified any conclusions that may be drawn about the efficacy of the threshold used with it.

In the experiments in Peru, a contact fungicide containing mancozeb was ap-
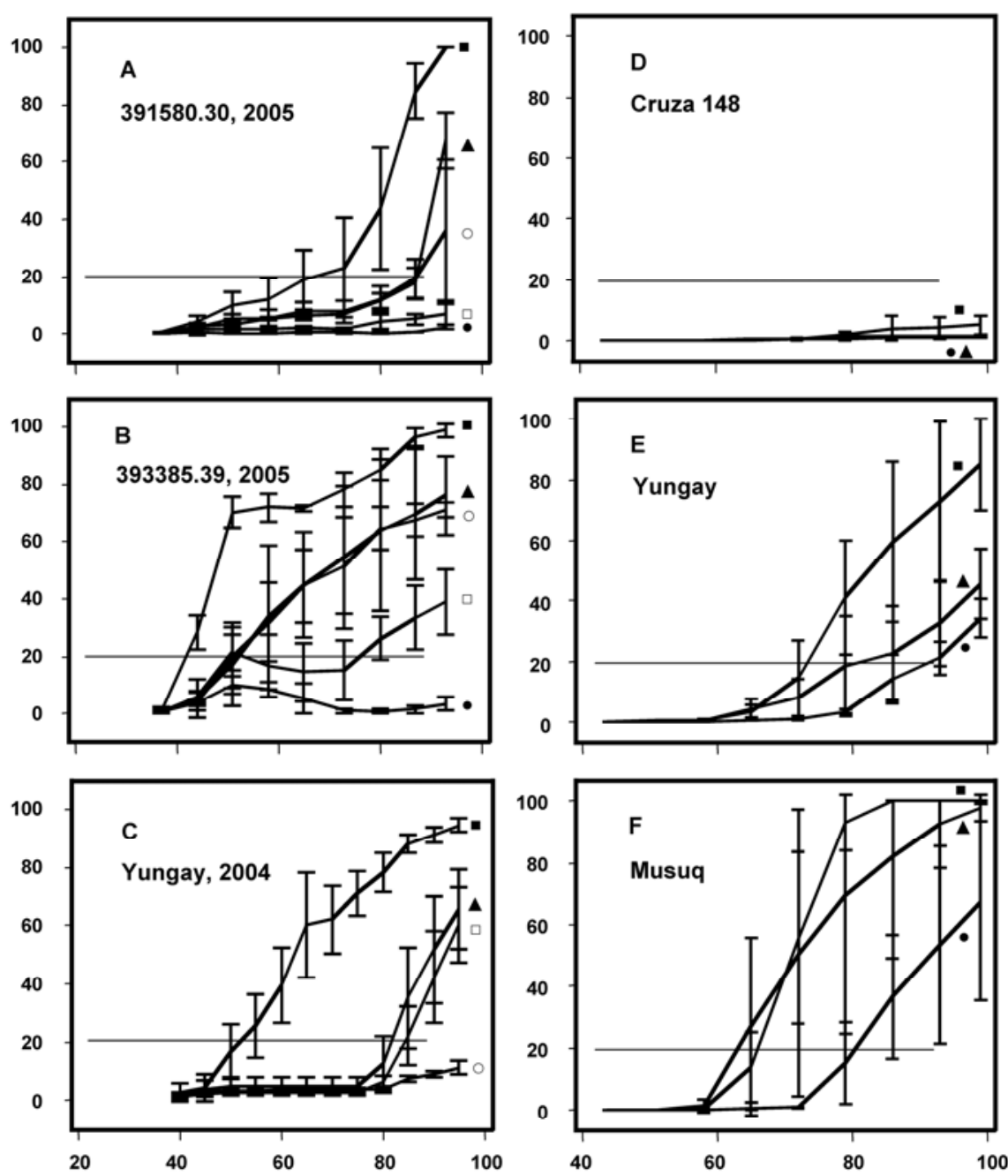

Peru 2004, 2005

Days after planting

Peru 2006

Fig. 3. Potato late blight (Phytophthora infestans) disease progress curves for epidemics in selected potato genotypes (name of cultivar or breeding line no. in upper left corner) in experiments in $\mathbf{C}$, Peru in 2004; $\mathbf{A}$ and B, 2005; and D, E, and F, 2006 with treatments consisting of fungicide regimes based on calendar spraying or rainfall thresholds. Error bars indicate standard deviations for replicate plots. Symbols $(\boldsymbol{\bullet}, \bigcirc, \boldsymbol{\Lambda}, \square$, and $\mathbf{\square})$ can be used to identify corresponding data described in Table 1 (e.g., $\mathbf{\square}$ = unsprayed treatment and $\boldsymbol{\bullet}$ = calendar spray treatment [5- or 7-day spray interval]). plied early in the season to protect emerging plants until they reached a minimum size for the experiment. In Ecuador, formulations containing the systemic fungicide propamocarb or the translaminar fungicide cymoxanil were used to protect the plants. It cannot be excluded that inoculum in the experiments came from infected tubers that were infected prior to emergence (27), but this phenomenon would be equally probable for all treatments. The contact fungicide applied weekly between $80 \%$ emergence and 30 days after planting in the experiments in Peru may not have been sufficient to protect plants and this may explain part of the apparent higher disease pressure observed in the Peruvian experiments.

The epidemics analyzed in this research indicated that spray regimes consisting of calendar sprays every 5 to 7 days with contact fungicides frequently do not provide successful late blight control with susceptible genotypes during the rainy season in the highlands of Peru and Ecuador. This observation is consistent with recent findings that farmers generally use translaminar-type fungicides with susceptible cultivars (26) and, in some cases, may use them exclusively (35).

Similarly, low-threshold treatments (i.e., 10 to $15 \mathrm{~mm}$ ) also were not effective with susceptible genotypes. The failure of low rainfall thresholds was probably due, at least in part, to the use of a minimum spray period, which was chosen with the idea that the regime should help to reduce the number of sprays and be practical for farmers. These results are in line with experiments conducted in the northeastern United States, where a low threshold combined with a minimum spray period also was not successful with a susceptible cultivar (17). In hindsight, low-threshold treatments probably should have been employed without the minimum periods, as in the low threshold treatments used in Colombia, which were successful without the use of minimum spray periods $(1,5)$. The minimum spray periods represent a confounding factor and hinder interpretation of results. Without the minimum spray periods, low thresholds may have protected susceptible genotypes better than the calendar spraying but they probably would have resulted in an increase in fungicide use. In this sense, the threshold would not be a tool for reducing fungicide use but, rather, for reducing risk of crop loss.

We assume that the earlier studies from Colombia were done with the "old" population (sensu Spielman; 38) of $P$. infestans, which has since been replaced by a new population throughout the Andean region (15). An increasing number of studies have shown that new populations are more difficult to manage than was the old population $(4,9,13,24,28-30)$. Therefore, it is likely that the successful thresholds of 13 and 25 $\mathrm{mm}$ found in the studies from the 1960s would be too high for managing suscepti- 
ble cultivars today with or without the use of minimum spray periods.

The criterion we used for determining successful control was arbitrary. We were tempted to use a statistical test to compare the thresholds with the calendar sprays but these spray regimes often were not successful; therefore, the interpretation of such a comparison is not clear. The $20 \%$ criterion may seem relatively high but it was chosen because even genotypes with moderate levels of resistance sometimes get infected near the end of the season, which may have little effect on yield (37). The RAUDPC may have been a good metric for defining a success criterion but this measure can be affected by inconsistency in the rate of disease increase. For example, in Peru in 2006, disease symptoms were detected near day 40 but the disease severity did not begin to increase rapidly until about day 60. This led to relatively low RAUDPC values in unsprayed $\mathrm{cv}$. Yungay (lower than in Peru in 2004), even though the disease progress curve was steep (Fig. 3).

The rainfastness of mancozeb has been shown to be highly dependent on its formulation partners and the characteristics of the leaf surface where it is deposited (i.e., rainfastness may be cultivar dependent; 23). Data that describe rainfall wash-off dynamics on potato for the commercial fungicide formulation of mancozeb, Dithane M-45, which we used, could help in the interpretation of our results and should be an objective of future research. Residuals of contact fungicide on the leaf surface were described as being exponentially related to rainfall (2), with increasing amounts of rain washing decreasing amounts of product. Therefore, smaller residual amounts of contact fungicide needed to protect a resistant cultivar would be less sensitive to rainfall and, therefore, easier to manage with accumulated rainfall thresholds. The higher residual amounts needed to protect a susceptible cultivar would be quickly lost with rainfall.

Accumulated rainfall is easy to measure and has proven easy to understand for resource-poor farmers. However, not all farmers have easy access to far-away fields and, for them, the calendar spray approach is the most practical. In one study, reducing contact fungicide input by lowering the dose resulted in less foliar disease than extending application intervals (30). Reduction of dose in calendar sprays according to accumulated rainfall may be another way of using this simple DSS to optimize fungicide use.

\section{ACKNOWLEDGMENTS}

This research was funded by the Danish International Development Assistance (DANIDA) and the International Potato Center (CIP).

\section{LITERATURE CITED}

1. Barriga, R., Thurston, H. D., and Heidrick, L. E. 1961. Ciclos de aspersión para el control de la "gota" de la papa. Agric. Trop. 17:617-622.

2. Bruhn, J. A., and Fry, W. E. 1982. A mathematical model of the spatial and temporal dynamics of chlorothalonil residues on potato foliage. Phytopathology 72:1306-1312.

3. Campbell, C. L., and Madden, L. V. 1990. Introduction to Plant Disease Epidemiology. John Wiley \& Sons, New York.

4. Carlisle, D. J., Cooke, L. R., Watson, S., and Brown, A. E. 2002. Foliar aggressiveness of Northern Ireland isolates of Phytophthora infestans on detached leaflets of three potato cultivars. Plant Pathol. 51:424-434.

5. Castaño, J. J., and Thurston, H. D. 1965. Aspersiones de maneb a distintos intervalos y niveles de lluvia para control de Phytophthora infestans en la papa. Agric. Trop. 21:25-32.

6. Cole, D. C., Carpio, F., Math J. J. M., and Léon, N. 1997. Dermatitis in Ecuadorean farm workers. Contact Dermatitis 37:1-8.

7. Cole, D. C., Sherwood, S., Crissman, C. C., Barrera, V., and Espinosa, P. 2002. Pesticides and health in highland Ecuadorian potato production: assessing impacts and developing responses. Int. J. Occup. Environ. Health 8:182190.

8. Crissman, C. C., Espinosa, P., Ducrot, C. E. H., Cole, D. C., and Carpio, F. 1998. The case study site: Physical, health, and potato farming systems in Carchi province. Pages 85-120 in: Economic, Environmental, and Health Tradeoffs in Agriculture: Pesticides and the Sustainability of Andean Potato Production. C. C. Crissman, J. M. Antle, and S. M. Capalbo, eds. Kluwer Academic Publishers and International Potato Center (CIP), Dordrecht, The Netherlands.

9. Day, J. P., and Shattock, R. C. 1997. Aggressiveness and other factors relating to displacement of populations of Phytophthora infestans in England and Wales. Eur. J. Plant Pathol. 103:379-391.

10. Devaux, A., and Haverkort, A. J. 1987. The effects of shifting planting dates and mulching on late blight (Phytophthora infestans) and drought stress of potato crops grown under tropical highland conditions. Exp. Agric. 23:325-333.

11. Fernández-Northcote, E. N., Navia, O., and Gandarillas, A. 2000. Basis of strategies for chemical control of potato late blight developed by PROINPA in Bolivia. Fitopatología 35:137-149.

12. Fife, J. P., and Nokes, S. E. 2002. Evaluation of the effect of rainfall intensity and duration on the persistence of chlorothalonil on processing tomato foliage. Crop Prot. 21:733-740.

13. Flier, W. G., and Turkensteen, L. J. 1999. Foliar aggressiveness of Phytophthora infestans in three potato growing regions in the Netherlands. Eur. J. Plant Pathol. 105:381388.

14. Forbes, G. A., Chacón, M. G., Kirk, H. G., Huarte, M. A., Van Damme, M., Distel, S., Mackay, G. R., Stewart, H. E., Lowe, R., Duncan, J. M., Mayton, H. S., Fry, W. E., Andrivon, D., Ellissèche, D., Pellé, R., Platt, H. W., MacKenzie, G., Tarn, T. R., Colon, L. T., Budding, D. J., Lozoya-Saldaña, H., Hernandez-Vilchis, A., and Capezio, S. 2005. Stability of resistance to Phytophthora infestans in potato: an international evaluation. Plant Pathol. 54:364-372.

15. Forbes, G. A., Escobar, X. C., Ayala, C. C., Revelo, J., Ordoñez, M. E., Fry, B. A., Doucett, K., and Fry, W. E. 1997. Population genetic structure of Phytophthora infestans in Ecuador. Phytopathology 87:375-380.

16. Forbes, G. A., and Landeo, J. A. 2006. Late Blight. Pages 279-320 in: Handbook of Potato Production, Improvement, and Postharvest Management. J. Gopal and K. S. M. P., eds. Haworth Press Inc., Binghamton, NY.

17. Fry, W. E. 1977. Integrated control of potato late blight: effects of polygenic resistance and techniques of timing fungicide applications. Phytopathology 67:415-420.

18. Fry, W. E. 1978. Quantification of general resistance of potato cultivars and fungicide effects for integrated control of potato late blight. Phytopathology 68:1650-1655.

19. Garrett, K. A., Nelson, R. J., Mundt, C. C., Chacón, G., Jaramillo, R. E., and Forbes, G. A. 2001. The effects of host diversity and other management components on epidemics of potato late blight in the humid highland tropics. Phytopathology 91:993-1000.

20. Hansen, J. G., Koppel, M., Valskyte, A., Turka, I., and Kapsa, J. 2005. Evaluation of foliar resistance in potato to Phytophthora infestans based on an international field trial network. Plant Pathol. 54:169-179.

21. Haverkort, A. J., and Bicamumpaka, M. 1986. Correlation between intercepted radiation and yield of potato crops infested by Phytophthora infestans in central Africa. Neth. J. Plant Pathol. 92:239-247.

22. Hijmans, R. J., Forbes, G. A., and Walker, T. S. 2000. Estimating the global severity of potato late blight with GIS-linked disease forecast models. Plant Pathol. 49:697-705.

23. Hunsche, M., Bringe, K., Schmitz-Eiberger, M., and Noga, G. 2006. Leaf surface characteristics of apple seedlings, bean seedlings and kohlrabi plants and their impact on the retention and rainfastness of mancozeb. Pest Manage. Sci. 62:839-847.

24. Kato, M., Mizubuti, E. S., Goodwin, S. B., and Fry, W. E. 1997. Sensitivity to protectant fungicides and pathogenic fitness of clonal lineages of Phytophthora infestans in the United States. Phytopathology 87:973-978.

25. Kirk, W. W., Abu-El Samen, F. M., Muhinyuza, J. B., Hammerschmidt, R., Douches, D. S., Thill, C. A., and Thompson, A. L. 2005. Evaluation of potato late blight management utilizing host plant resistance and reduced rates and frequencies of fungicide applications. Crop Prot. 24:961-970.

26. Kromann, P., Leon, D., Taipe, A., AndradePiedra, J. L., and Forbes, G. A. 2008. Comparison of two strategies for use of translaminar and contact fungicide in the control of potato late blight in the highland tropics of Ecuador. Crop Prot. 27:1098-1104.

27. Kromann, P., Taipe, A., Andrade-Piedra, J. L., Munk, L., and Forbes, G. A. 2008. Preemergence infection of potato sprouts by Phytophthora infestans in the highland tropics of Ecuador. Plant Dis. 92:569-574.

28. Miller, J. S., Johnson, D. A., and Hamm, P. B. 1998. Aggressiveness of isolates of Phytophthora infestans from the Columbia Basin of Washington and Oregon. Phytopathology 88:190-197.

29. Mizubuti, E. S. G., and Fry, W. E. 1998. Temperature effects on developmental stages of isolates from three clonal lineages of Phytophthora infestans. Phytopathology 88:837843.

30. Nærstad, R., Hermansen, A., and Bjor, T. 2007. Exploiting host resistance to reduce the use of fungicides to control potato late blight. Plant Pathol. 56:156-166.

31. Neely, D. 1970. Persistence of foliar protective fungicides. Phytopathology 60:1583-1586.

32. Nelson, R., Mundt, C., Orrego, R., Ortiz, O. Fredrix, M., Tenorio, J., and Vien, N. V. 2001. Working with resource-poor farmers to manage plant diseases. Plant Dis. 85:684-695.

33. Ortiz, O., Garrett, K. A., Heath, J. J., Orrego, R., and Nelson, R. J. 2004. Management of potato late blight in the Peruvian highlands: Evaluating the benefits of farmer field schools and farmer participatory research. Plant Dis. 88:565-571.

34. Ortiz, O., Winters, P., and Fano, H. 1999. La percepción de los agricultores sobre el pro- 
blema del tizón tardío o rancha y su manejo: estudios de casos en Cajamarca, Perú. Rev. Latinoamericana Papa 11:97-120.

35. Oyarzún, P., Garzón, C., Leon, D., Andrade, I., and Forbes, G. 2005. Incidence of potato tuber blight in Ecuador. Am. J. Potato Res. 82:117122.

36. Oyarzún, P. J., Taipe, J. A., and Forbes, G. A. 2001. Phytophthora infestans characteristics and activity in Ecuador-country profile. Pages 15-25 in: Proc. Int. Workshop "Complementing resistance to late blight (Phy- tophthora infestans) in the Andes." E. N. Fernández-Northcote, ed. Cochabamba, Bolivia. International Potato Center (CIP), Lima, Peru.

37. Shtienberg, D., Bergeron, S. N., Nicholson, A. G., Fry, W. E., and Ewing, E. E. 1990. Development and evaluation of a general-model for yield loss assessment in potatoes. Phytopathology 80:466-472.

38. Spielman, L. J., Drenth, A., Davidse, L. C., Sujkowski, L. J., Gu, W., Tooley, P. W., and Fry, W. E. 1991. A second world-wide migra- tion and population displacement of Phy tophthora infestans? Plant Pathol. 40:422-430.

39. Valcke, M., Chaverri, F., Monge, P., Bravo, V., Mergler, D., Partanen, T., and Wesseling, C. 2005. Pesticide prioritization for a casecontrol study on childhood leukemia in Costa Rica: a simple stepwise approach. Environ. Res. 97:335-347.

40. Wesseling, C., Corriols, M., and Bravo, V. 2005. Acute pesticide poisoning and pesticide registration in Central America. Toxicol. Appl Pharmacol. 207:S697-S705. 